\title{
GT2021-59688
}

\section{EVALUATION OF THERMOACOUSTIC APPLICATIONS USING WASTE HEAT TO REDUCE CARBON FOOTPRINT}

\author{
Philip Spoor, \\ Independent consultant, formerly Chart Industries, \\ Ball Ground, USA \\ Deoras Prabhudharwadkar, Srinath Somu, Saumitra Saxena, Deanna Lacoste, William Roberts \\ Clean Combustion Research Center, King Abdullah University of Science and Technology (KAUST), \\ Thuwal, Saudi Arabia
}

\begin{abstract}
Thermoacoustics (TA) engines and refrigerators typically run on the Stirling cycle with acoustic networks and resonators replacing the physical pistons. Without moving parts, these TA machines achieve a reasonable fraction of Carnot's efficiency. They are also scalable, from fractions of a Watt up to $\mathrm{kW}$ of cooling. Despite their apparent promise, TA devices are not in widespread use, because outside of a few niche applications, their advantages are not quite compelling enough to dislodge established technology.

In the present study, the authors have evaluated a selected group of applications that appear suitable for utilization of industrial waste heat using TA devices and have arrived at a ranked order. The principal thought is to appraise whether thermoacoustics can be a viable path, from both an economic and energy standpoint, for carbon mitigation in those applications. The applications considered include cryogenic carbon capture for power plant exhaust gases, waste-heat powered air conditioning/water chilling for factories and office buildings, hydrogen liquefaction, and zero-boiloff liquid hydrogen $\left(\mathrm{LH}_{2}\right)$ storage. Although the criteria used for evaluating the applications are somewhat subjective, the overall approach has been consistent, with the same set of criteria applied to each of them. Thermoeconomic analysis is performed to evaluate the system viability, together with overall consideration of a thermoacoustic device's general nature, advantages, and limitations.

Our study convincingly demonstrates that the most promising application is zero-boiloff liquid hydrogen storage, which is physically well-suited to thermoacoustic refrigeration and requires cooling at a temperature and magnitude not ideal for standard refrigeration methods. Waste-heat powered air conditioning ranks next in its potential to be a viable commercial application. The rest of the applications have been found to have
\end{abstract}

relatively lower potentials to enter the existing commercial space.

Keywords: Thermoacoustics, waste-heat recovery

\section{INTRODUCTION}

Thermoacoustics, or the transduction of heat into sound and sound into heat flux, has long been considered a potential game-changer in the areas of energy and refrigeration. Thermoacoustic devices can operate on something akin to a Stirling cycle [1] and achieve a significant fraction of Carnot's efficiency without moving parts. Coolers can efficiently operate over small ambient temperature differences or reach cryogenic temperatures. At the same time, thermoacoustic engines (like Stirling engines) are "external combustion" and can make use of any heat source, either from primary fuel or exhaust. Despite this suite of attributes, thermoacoustics has not become established in any industries except cryogenic cooling, in the capacity range of a few watts to a few thousand watts, driven by electricity. In most other cases, there is a more established, more economical, or more efficient alternative. Even the absence of moving parts, long considered a potentially decisive advantage for thermoacoustic engines and coolers, is of only moderate interest outside of specialized circumstances like spacecraft and satellites, where maintenance is impossible, and failures are catastrophic.

One limitation in adopting thermoacoustic technology has been in electrical transduction. While thermoacoustic coolers require no moving parts in the cold regions, they still require acoustic power, which is typically supplied by a 'linear compressor,' which uses linear motors to provide a pressure wave. Engine-generators, which use heat to produce electricity, requires a means of extracting power, which has typically been a linear alternator. Linear motors are simply more costly, more failure-prone, and more challenging to scale than rotary motors. 
On the other hand, an acoustic engine directly driving an acoustic refrigerator avoids linear motors or alternators and the associated transduction losses. This may be a promising configuration for industrial applications.

Obtaining refrigeration from heat, especially from lowgrade sources, could reduce energy consumption and carbon footprint. Heat-driven refrigeration is still relatively uncommon in the industrial world, confined mostly to adsorption cycles, which are recognized as inefficient. Heat-driven thermoacoustic refrigeration offers a more efficient alternative while preserving the absence of moving parts that make absorption refrigerators attractive for low-maintenance installations. Thermoacoustic heat-driven refrigerators will not be compact, however. The selfoscillation of the engine requires a resonator for tuning and acoustic energy storage, which is typically close to a quarterwavelength long. Most acoustic refrigerators, especially cryogenic ones, use helium as the working fluid, and the high speed of sound in helium results in long wavelengths, hence long resonators. Typical frequencies of acoustic refrigerators, $100 \mathrm{~Hz}$ to $20 \mathrm{~Hz}$, indicate resonator lengths on the order of 3 to $13 \mathrm{~m}$. These resonators are made from substantial pressure-vessel components, rather than being narrow tubes that can be coiled, for instance.

\section{CRITERIA FOR EVALUATION}

The criteria used for the evaluation of various possible applications are somewhat subjective. Simple calculations are used where possible, together with overall consideration of a thermoacoustic device's general nature, advantages, and limitations. We consider the practicality of an application, its basic economics, and a rough evaluation of the opportunity cost by asking these questions:

1. Does the use of a thermoacoustic device offer an improvement over current practice? Or,

2. Does a thermoacoustic device enable a process or technology that is currently not practical?

3. In a given application, will a thermoacoustic device make good use of the resources in question, or could they be put to better use?

\section{Applications under consideration}

This paper considers the following uses of thermoacoustic (T.A.) technology:

1. Cryogenic Carbon Capture: This builds on an effort already underway at KAUST to freeze carbon out of combustion products by using the waste heat in those combustion products if possible [2]. The complex physical process of capturing and removing frozen $\mathrm{CO}_{2}$ using cold surfaces is well-developed through an existing partnership between KAUST and Sustainable Energy Solutions. A heatpowered TA cooler would provide the cold surfaces.

2. Waste-heat powered air conditioning/water chilling for factories and office buildings: This has long been a dream of sustainable energy advocates and is being pursued in other parts of the world by a team led by notable thermoacoustic researcher Kees de Blok [3].
3. Hydrogen liquefaction: Saudi Arabia is investing heavily in preparation for a post-hydrocarbon economy, in which hydrogen may play a significant part. The Kingdom's abundant sunlight can be used to electrolyze water into $\mathrm{H}_{2}$ and $\mathrm{O}_{2}$ sustainably; themoacoustic cooling could enable liquefaction of the hydrogen using solar or waste heat.

4. Zero-boiloff liquid hydrogen $\left(\mathbf{L H}_{2}\right)$ storage: Stored liquid hydrogen will slowly boil off unless a means of recondensing the liquid is included in the storage tanks. Because liquid hydrogen is stored at a much lower temperature $(20 \mathrm{~K})$ than other common cryogens like $\mathrm{LN}_{2}$ or LNG (80-90K and 130$160 \mathrm{~K}$, respectively), heat leak into $\mathrm{LH}_{2}$ storage tanks is proportionally higher.

\section{THERMOACOUSTIC CRYOCOOLER}

The schematic of the KAUST-cryocooler (under development) is shown in Figure 1 to illustrate the functioning of a thermoacoustic device. It is similar to the TASHE (Thermoacoustic Stirling Heat Engine) developed at Los Alamos in the 1990's [4], but with a shell-and-tube heat exchanger to extract heat from an external hot gas source, instead of the internal Nichrome heaters used in the Los Alamos engine. Hot gas flows transversely through the shell of this hot heatexchanger (HHX), while the helium working fluid oscillates axially inside the tubes. Adjacent to the HHX is a stack of wire mesh that functions as the regenerator, followed by an ambient, water-cooled shell-and-tube heat exchanger (AHX). These three elements comprise the thermal core of a Stirling-cycle device. The torus provides feedback of acoustic power. With a large enough thermal gradient imposed on the regenerator, small acoustic oscillations will be amplified as they pass through the thermal core and a self-sustaining traveling wave is maintained in the torus. A pulse-tube cryocooler is attached to the engine via a transfer tube, which absorbs some of the acoustic work produced by the engine and turns it into cryogenic cooling, using the same Stirling cycle in reverse. This design is expected to draw about 150 watts of acoustic power from the engine, sufficient to freeze $\mathrm{CO} 2$ supplied to a glass dewar surrounding the cold tip, providing a compelling visual demonstration of $\mathrm{CO} 2$ freezing powered by waste heat.

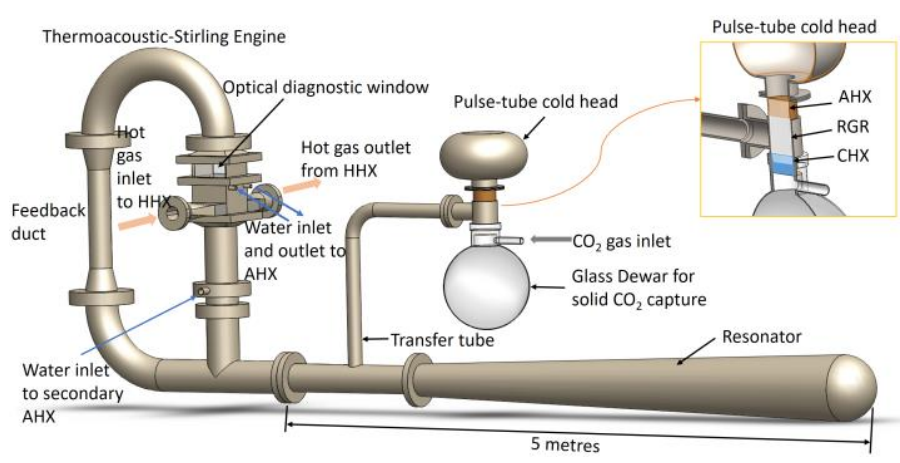

FIGURE 1: SCHEMATIC OF TASHE DRIVING PULSE-TUBE CRYOCOOLER UNDER DEVELOPMENT BY KAUST 


\section{EVALUATION OF THERMOACOUSTIC APPLICATIONS}

\subsection{Cryogenic Carbon Capture:}

Along with using cleaner energy sources, carbon capture and sequestration is an important strategy for reducing carbon emissions. Most methods employ a catalyzed chemical process, but because $\mathrm{CO}_{2}$ freezes at a temperature much warmer than air but considerably colder than water vapor, it can in principle be selectively removed from an exhaust stream by forcing the exhaust through a heat exchanger with surfaces cold enough to freeze out all or most of the $\mathrm{CO}_{2}$. KAUST has been partnering with Utah-based Sustainable Energy Solutions (SES) to field-test cryogenic carbon capture technology. Figure 2 shows a schematic of the process:

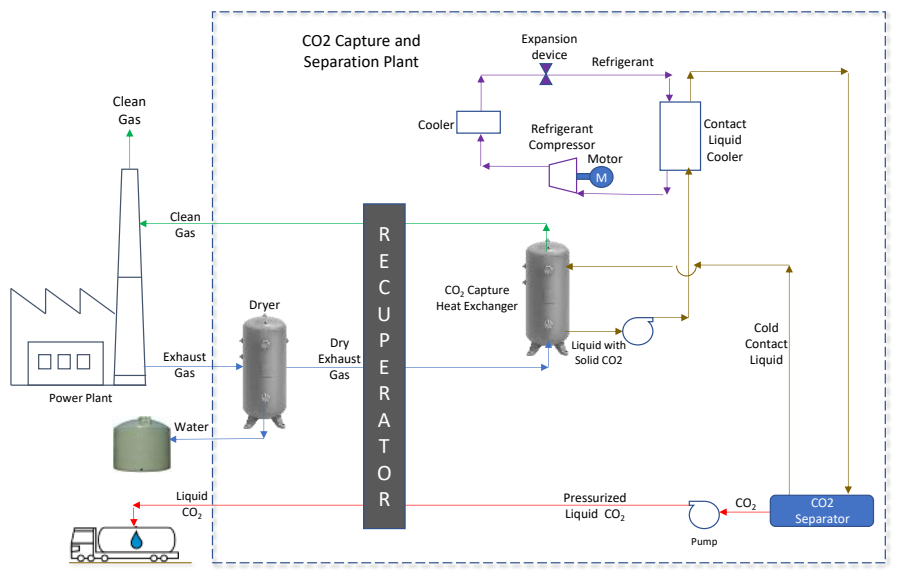

FIGURE 2: SIMPLE SCHEMATIC OF THE CCC PROCESS, FROM SES.

SES argues that even with a conventional electrically-driven refrigeration cycle, cryogenic carbon capture is more energyefficient than the alternatives, such as amine scrubbing [5]. If the freezing is accomplished with a waste-heat powered refrigeration cycle, this further enhances the argument for CCC. An especially strong case emerges if a refrigeration cycle powered by the waste heat produced by a power plant can be used to capture the carbon emitted by that same plant.

\subsection{Thermoacoustic Cryogenic Carbon Capture powered by single-cycle power plant exhaust}

Kingdom of Saudi Arabia (KSA) has a large number of "single-cycle" power plants, meaning that these plants do not fully recuperate the exhaust heat and use it to power a lowertemperature cycle, such as a steam turbine, in addition to the main cycle (e.g., a high-temperature gas turbine). The fundamental difference between a single-cycle, or simple-cycle, plant, and a more efficient "combined cycle" plant is shown in Figure 3.

According to KSA's Electricity and Cogeneration Regulatory Authority (ECRA) "Statistical Booklet" for 2018 [6], out of 684 active power plants, KSA had 416 single-cycle gasturbine plants, accounting for $34.9 \%$ of generation capacity.
Aside from the apparent strategy of upgrading or replacing these with combined-cycle systems, KSA is looking for alternative ways of utilizing the waste heat from these plants. One option is to use the exhaust waste heat to power a heat-driven refrigerator that captures the carbon in that same exhaust.

General Electric's 7E Series gas turbines are most common in the Kingdom, so data from these can be considered representative. Selected data for the GE 7E turbine are shown in Table 1 [7].

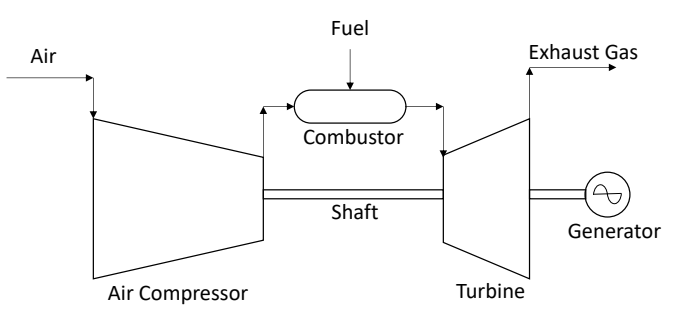

(A)

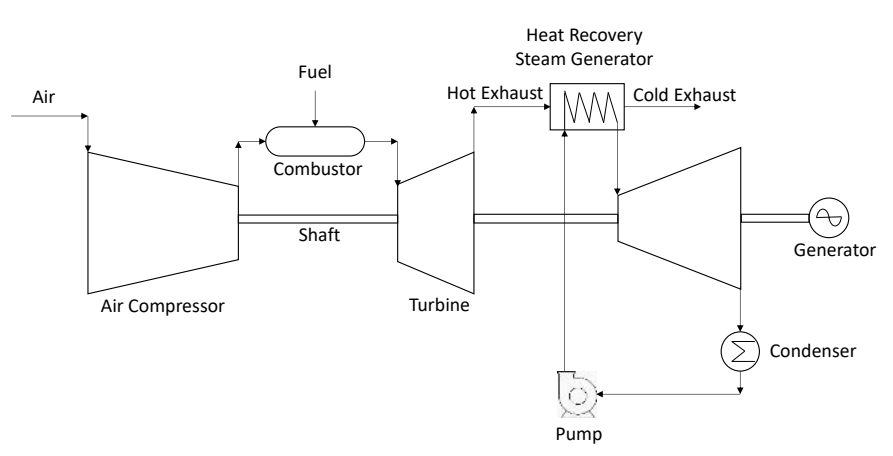

(B)

FIGURE 3: (A) SINGLE-CYCLE, OR SIMPLE-CYCLE, GAS TURBINE GENERATOR; (B) COMBINED-CYCLE GENERATOR.

Table 1: NOMINAL CHARACTERISTICS OF THE GENERAL ELECTRIC 7E GAS TURBINE.

\begin{tabular}{|l|l|l|}
\hline OEM \& Model & & GE 7E.03 \\
\hline Year & & 1984 \\
\hline ISO Base Rating & {$[\mathrm{kW}]$} & 91000 \\
\hline Heat Rate & {$[\mathrm{BTU} / \mathrm{kWh}]$} & 10060 \\
\hline Efficiency & {$[\%]$} & 33.9 \\
\hline Flow & {$[\mathrm{lb} / \mathrm{sec}]$} & 650 \\
\hline Exhaust Temp & {$[\mathrm{C}]$} & 550 \\
\hline
\end{tabular}

According to these data, the exhaust temperature is $550^{\circ} \mathrm{C}$, far lower than flame temperature but much higher than the typical exhaust temperature from a combined-cycle plant, which can be as low as $90^{\circ} \mathrm{C}$. In a combined-cycle plant, this high exhaust temperature would be used to make steam to run a steam turbine. Here, we explore how it could be used to run a thermoacoustic engine and refrigerator to freeze $\mathrm{CO}_{2}$ from that exhaust. We can examine whether there is enough exergy in the 
waste heat stream to remove the carbon, given reasonable assumptions about the engine and cooler efficiencies.

\subsubsection{Input conditions and assumptions}

The hot-end temperature of the engine is determined by how much of the exhaust heat we expect to capture. The more heat that is harvested, the cooler the final exhaust and the hot-heatexchanger temperature. There is a tradeoff between capturing more of the available waste heat, which increases the power in the cycle, and preserving the high exhaust temperature, which lifts the cycle efficiency. If we assume that we can capture half the exhaust heat, and also assume a hot ambient temperature of, say, $310 \mathrm{~K}$ (about $100 \mathrm{~F}$ - representative of Saudi Arabia) then the final exhaust temperature is around $567 \mathrm{~K}$, or $294^{\circ} \mathrm{C}$, and the hot HX temperature is roughly halfway between the turbine exhaust and final exhaust temperature, or about $695 \mathrm{~K}\left(422^{\circ} \mathrm{C}\right)$.

The cold-end temperature determines how thoroughly the carbon is scrubbed from the exhaust. Although atmosphericpressure $\mathrm{CO}_{2}$ freezes at $-78.5^{\circ} \mathrm{C}(194.7 \mathrm{~K})$, the cold $\mathrm{HX}$ temperature must be considerably below this nominal freezing point to capture all or most of the carbon in flowing exhaust, with very limited contact time between the exhaust and the cold surfaces. Capturing $99 \%$ of the carbon from flue gas at atmospheric pressure requires a surface temperature of nearly $-140^{\circ} \mathrm{C}$, or $133 \mathrm{~K}$.

Together, the cycle temperatures are $567 \mathrm{~K}$ for the hot end, $310 \mathrm{~K}$ for ambient heat rejection, and $133 \mathrm{~K}$ for the cold heat acceptor. These, combined with the heat and mass-flow numbers from Table 1, are used to determine whether a self-contained refrigeration cycle driven only by the waste heat itself can capture the carbon in the exhaust.

\section{Additional assumptions}

In order to calculate the heat load on the cold surfaces, some assumptions must be made about the overall thermal management. In this case, we make the optimistic assumption that the heat flows in this process are fully recuperated, that is, the captured $\mathrm{CO}_{2}$ stream and remaining cold flue gas are used to pre-cool the incoming flue gas down nearly to the nominal $\mathrm{CO}_{2}$ freezing point (presumably after it exits the hot heat-exchanger of the engine). In this application, the $\mathrm{CO}_{2}$ is reheated anyway, for either industrial use or for eventual sequestration under pressure, so the only net cold thermal load is the latent heat of sublimation of the $\mathrm{CO}_{2}$ plus the additional cooling to bring the solid down to $133 \mathrm{~K}$.

\subsubsection{Results}

Evaluating this application requires estimating the total mass flow of carbon in the flue gas, the cooling capacity that can be generated from the available waste heat, and the enthalpy change required to freeze out the $\mathrm{CO}_{2}$. As one might expect, the results are very sensitive to the assumed efficiencies of the engine and cooler.

From Table 1, the mass flow of air through the GE $7 \mathrm{E}$ turbine is $650 \mathrm{lb} / \mathrm{s}$, or $\dot{m}_{\text {air }}=295 \mathrm{~kg} / \mathrm{s}$. We also have the process temperatures:

$$
\begin{aligned}
& T_{X T}=823 \mathrm{~K}(\text { Gas Turbine exhaust }) \\
& T_{X F}=567 \mathrm{~K}(\text { Final exhaust from TA device })
\end{aligned}
$$

$$
\begin{aligned}
& T_{H}=695 \mathrm{~K} \text { (Hot HX temperature) } \\
& T_{A}=310 \mathrm{~K} \text { (Ambient } / \text { reject temperature) }
\end{aligned}
$$

Using the heat capacity of air at $c_{\text {Pair }}=1.00 \mathrm{~kJ} / \mathrm{kg} / \mathrm{K}$; capturing half the available heat in the flue gas means $\dot{Q}_{H}=$ $\dot{m} C_{p} \Delta T=295 \mathrm{~kg} / \mathrm{s} \times 1 \mathrm{~kJ} / \mathrm{kg} / \mathrm{K} \times(823-567) \mathrm{K}=75.6 \mathrm{MW}$. From Table 1, the nominal power rating of the $7 \mathrm{E} .03$ turbine is 91 M.W.; so the ratio of heat into our engine, vs. power from the turbine, is

$$
\frac{\dot{Q}_{H}}{\dot{W}_{\text {elec }}} \sim 0.83 .
$$

Calculating the cooling power produced from this heat requires assumed efficiencies for the thermoacoustic engine and cooler. It is safe to assume that this will be a relatively large-scale thermoacoustic device compared to most lab prototypes. Hence, it will benefit from a lower surface-to-volume ratio (this reduces resonator loss as a fraction of acoustic power in an engine). Well-designed acoustic engine prototypes [4] have efficiencies of $40 \%$ of Carnot if you include power into the resonator as well as the acoustic load. One thing in our favor is that the acoustic power is consumed directly by the cooling cycle, without any intervening transduction. As an optimistic upper bound, then, we could assume $\eta_{C}=0.40$ for both the engine and the cooler. The engine and cooler efficiencies are then,

$$
\begin{aligned}
& \text { Engine efficiency } \frac{\dot{W}_{A C}}{\dot{Q}_{H}}=\frac{T_{H}-T_{A}}{T_{H}} \eta_{C} \\
& =\frac{695-310}{695} 0.4=0.22 \text {. } \\
& \text { Refrigerator efficiency } \frac{\dot{Q}_{C}}{\dot{W}_{A C}}=\frac{T_{C}}{T_{A}-T_{C}} \eta_{C} \\
& =\frac{133}{310-133} 0.4=0.30 \text {. }
\end{aligned}
$$

The combined efficiency of the engine driving cooler is the product of the two, or

$$
\begin{aligned}
\text { Cooling from Heat ratio } & =\frac{\dot{Q}_{C}}{\dot{Q}_{H}} \\
=0.22 & \times 0.301=0.067 .
\end{aligned}
$$

Combining Eqs. (1) and (4) gives:

$$
\begin{aligned}
\text { Cooling per Turbine Power Rating } & =\frac{\dot{Q}_{C}}{\dot{W}_{\text {elec }}} \\
=0.067 \times 0.83 & =0.055 .
\end{aligned}
$$

Whether this cooling is adequate to capture the flue gas $\mathrm{CO}_{2}$ depends in part on what fuel is burned. Methane has a molecular weight of $12+1 \times 4=16$ grams per mole. If all the carbon in a stream of methane were oxidized into $\mathrm{CO}_{2}$, molecular weight $12+16 \times 2=44 \mathrm{~g} / \mathrm{mole}$, the $\mathrm{CO}_{2}$ yield is $44 / 16=2.75 \mathrm{~kg}$ per $\mathrm{kg}$ of $\mathrm{CH}_{4}$. The "heat content" of methane is approximately

$$
\Delta h_{\mathrm{CH} 4}=891 \mathrm{~kJ} / \mathrm{mol}=55.7 \mathrm{MJ} / \mathrm{kg} \text {. }
$$

Hence, yield of $\mathrm{CO}_{2}$ is $2.75 \mathrm{~kg} /(55.7 \mathrm{MJ} / \mathrm{kg})=4.9 \times 10^{-8}$ $\mathrm{kg} / \mathrm{J}$ of fuel heat energy. 
For the kind of turbine under consideration here, the nominal efficiency is $33.9 \%$ thermal-to-electric (Table 1). Hence,

$\mathrm{CO}_{2}$ yield per joule of electricity $=$

$$
4.9 \times 10^{-8} \mathrm{~kg} / \mathrm{J} / 0.339=1.5 \times 10^{-7} \mathrm{~kg} / \mathrm{J}
$$

Since $1 \mathrm{kWh}=3.6 \times 10^{6}$ joules, we finally obtain

$$
\begin{gathered}
\text { Methane Fuel } \mathrm{CO}_{2} \text { yield }=\left.\frac{m_{\mathrm{CO}_{2}}}{W_{\text {elec }}}\right|_{C_{4}} \\
=0.525 \mathrm{~kg} / \mathrm{kWh} .
\end{gathered}
$$

For our calculations, it might be appropriate to use the average of the published values for natural gas and oil, $(0.5+$ $0.7) / 2=0.6 \mathrm{~kg} / \mathrm{kWh}$, because the plants in Saudi Arabia may run on oil or gas (but rarely on coal):

$$
\begin{aligned}
& \text { Average Fuel } \mathrm{CO}_{2} \text { yield }=\frac{m_{\mathrm{CO}_{2}}}{W_{\text {elec }}} \\
& \approx 0.6 \mathrm{~kg} / \mathrm{kWh} \text {. }
\end{aligned}
$$

Finally, the amount of cooling required is found from the latent heat and heat capacity of $\mathrm{CO}_{2}$. The assumption is that the cold surfaces remove the latent heat of sublimation and further cool the solid carbon dioxide from the freezing point (194.7 K) to $133 \mathrm{~K}$. From the NIST Chemistry WebBook [8],

$$
\begin{aligned}
\Delta h_{S U B} & =571 \mathrm{~kJ} / \mathrm{kg}, \text { and } \\
c_{P} & =50 \mathrm{~J} / \mathrm{kg} / \mathrm{K} .
\end{aligned}
$$

Hence, the total enthalpy change is

$$
\begin{aligned}
\Delta h=\Delta h_{S U B}+c_{P} & \Delta T \\
& =571,000 \\
& +50(194.7-133) \\
& =6.41 \times 10^{5} \mathrm{~J} / \mathrm{kg} .
\end{aligned}
$$

Combining Eqs. (9) and (12),

Enthalpy change per $\mathrm{kW}$ of generator power

$$
=\frac{\Delta \dot{h}}{\dot{W}_{\text {elec }}}=0.107 \mathrm{~kW} / \mathrm{kW} .
$$

Combining this with Eq.(5) finally yields

Cooling power versus required enthalpy change

$$
=\frac{Q_{\mathrm{C}}}{\Delta h}=0.518 \text {. }
$$

In other words, even with some optimistic assumptions, a refrigeration cycle powered by the heat in a single-cycle power plant's exhaust could only remove about half the carbon in that exhaust.

Figure 4 shows the results if the engine and cooler are assumed to have the same fraction of Carnot's efficiency:

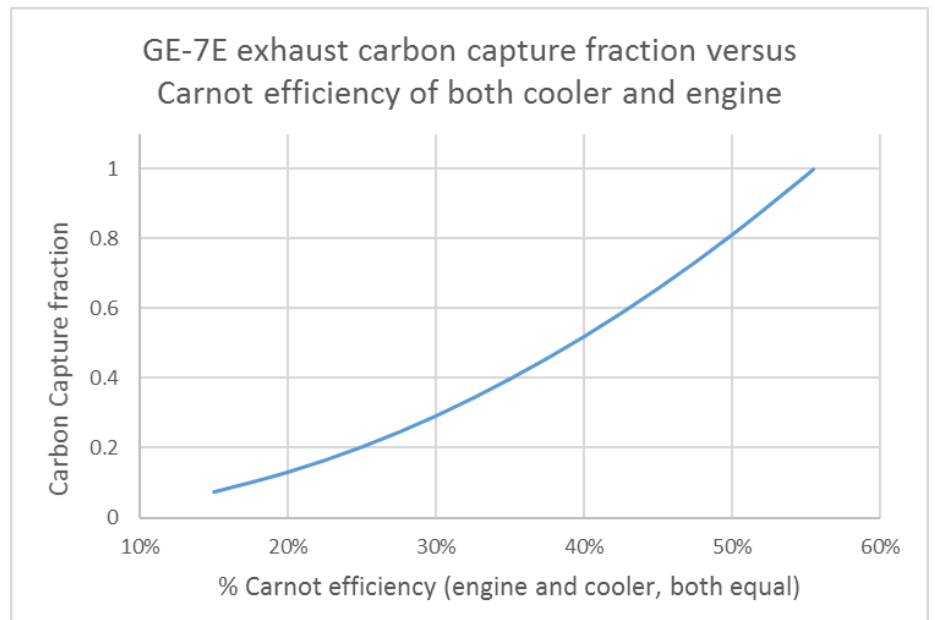

Figure 4: ESTIMATED FRACTION OF THE CO2 IN $550^{\circ} \mathrm{C}$ FLUE GAS THAT COULD BE CAPTURED WITH A HEATDRIVEN REFRIGERATION SYSTEM.

Since the engine and cooler efficiencies are multiplied to get the overall efficiency, the carbon-capture fraction is essentially quadratic in \% Carnot. Of course, the engine and cooler don't necessarily have the same Carnot efficiency and probably wouldn't, but this assumption helps illustrate the challenge of using waste-heat from flue gas to freeze carbon from that same flue gas. If both engine and cooler have a respectable $30 \%$ of Carnot's efficiency, then only $1 / 4$ of the $\mathrm{CO}_{2}$ can be captured. Even at $40 \%$ each, only half is captured. To capture it all would require an unlikely $55 \%$ of Carnot from both engine and cooler.

However, even if $100 \%$ of the carbon in a power plant cannot be scrubbed with cryogenics, using only the waste heat from the plant itself, even $50 \%$ or $25 \%$ capture is worthwhile if it is "free," i.e., requiring no external power source. This argument applies equally well to upgrading or replacing existing single-cycle power plants with combined-cycle plants (thus lowering their carbon emissions per $\mathrm{kWh}$ ). After the upgrade or replacement, the increased efficiency and lower emissions are "free"; it is the capital cost and plant downtime that are balanced against these benefits. Since single-cycle plants persist in the Kingdom, capital cost and convenience have won the argument thus far. The question is whether a thermoacoustic carboncapture system could be installed less expensively than bottoming steam cycle. That is hard to answer definitively since TA hardware is not standard, but some estimates may be attempted by considering the scale of the hardware required.

A TA engine running between the previously determined hot-end and ambient temperatures of $695 \mathrm{~K}$ and $310 \mathrm{~K}$, with $30 \%$ of Carnot's efficiency, will have a $1^{\text {st }}$-law efficiency of $17 \%$. From the above calculations, the heat captured by the engine at this hot-end temperature is approximately $75.6 \mathrm{MW}$, so the acoustic power produced by a $17 \%$-efficient engine would be $75.6 \times 0.17=12.8 \mathrm{MW}$. This is larger by several orders of magnitude than the largest thermoacoustic device ever made, to date, which is the so-called "Tower of Power" thermoacoustic natural-gas liquefier prototype built by Los Alamos and Praxair in 2000 [9]. It may even be an order of magnitude larger than any 
thermoacoustic device that has been contemplated. In their report on the development of the liquefier, Wollen et al. [9] present a concept drawing for a 10,000 gpd TA liquefier that could be installed on ships or on offshore platforms. The design point acoustic power in this device is $1 \mathrm{M} . \mathrm{W}$., and their illustration is shown alongside an image of GE's 7E.03 turbine in Figure 5. The $1 \mathrm{MW}$ engine is roughly half the size of the GE turbine already, and for the CCC application it would have to be 13 M.W., implying a cross section 13 times bigger, e.g. a diameter three and a half times larger. With such a large diameter, the length would have to increase to maintain sane aspect ratios in the main components, or several separate TA devices would have to be employed. Thus, the TA hardware in the power plant would be physically larger than the turbine itself. It seems doubtful that building such hardware into the plant to capture a fraction of the $\mathrm{CO}_{2}$ in the exhaust would be cost-effective, even if the operating cost were low. The counterargument is that TA devices are mostly just pipes, having no moving parts with exact tolerances, so while the engines may be large, they would not be extraordinarily costly.

Perhaps another perspective is helpful here. Standard turbomachinery could be used to extract power from the waste heat and provide cooling to freeze $\mathrm{CO}_{2}$; it would involve a steam turbine (similar to what would be required for a bottoming cycle) directly driving a compressor and expander for a turbo-Brayton or SMR (single-mixed-refrigerant) cycle. Steam-driven turbine chillers are already integrated into power plants as another form of waste-heat recovery. The scale of the cooling power required in the CCC application is a good fit to existing industrial refrigeration methods; from Table 1 and Eq. (13) above, the cooling power required is on the order of $10 \mathrm{MW}$ This is enormous for thermoacoustic machines but common for industrial chillers and air-separation plants.

Our subjective conclusion here is that while thermoacoustic carbon capture is possible, in principle, it does not appear to be an ideal application at this stage of TA development. According to the three criteria given in the introduction:

1. Does the use of a thermoacoustic device offer an improvement over current practice? In current practice, in Saudi Arabia, single-cycle plant waste heat is not utilized, so TA-CCC would be an improvement in that sense.

2. Does a thermoacoustic device enable a process or technology that is currently not practical? This is questionable since steam-driven chilling is currently practical. The issue is whether large TA devices without moving parts would be more cost-effective than standard turbomachinery. The scale-up from existing TA technology is so extreme that at the very least, the technology readiness level (TRL) of thermoacoustics in this area is very low.

3. In a given application, will a thermoacoustic device make good use of the resources in question, or could they be put to better use? Single-cycle power plants could be converted to combined-cycle or CHP plants, and the scale of cooling is appropriate for current industrial cooling methods. Therefore, a TA-CCC retrofit may not be the best use of resources.

\section{Cryogenic Carbon Capture Subjective score: $\mathbf{3 / 1 0}$}
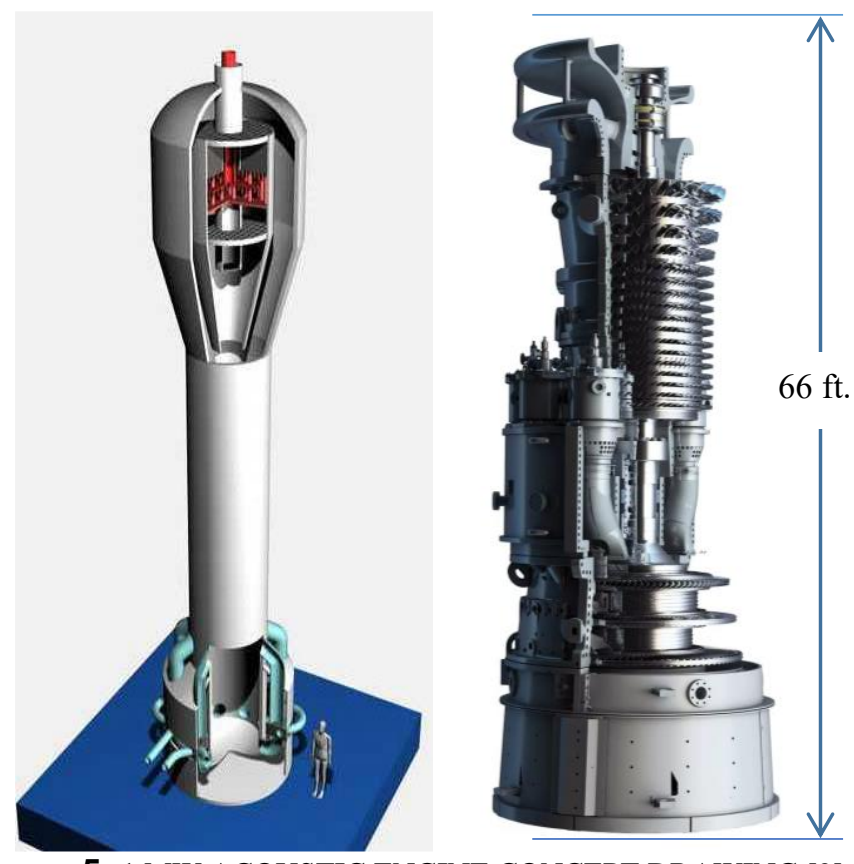

Figure 5: $1 \mathrm{MW}$ ACOUSTIC ENGINE CONCEPT DRAWING [9], ON LEFT, AND 91MW GE 7E.03 TURBINE [7], RIGHT.

\subsection{Waste-heat powered air-conditioning}

So much of the world's electricity is used for airconditioning, as much as $70 \%$ in hot climates like Saudi Arabia's, that it is naturally a target for any conservation strategy. Ambient cooling powered by waste heat is a Holy Grail of sustainable energy use.

Aster Thermoacoustics, an R\&D firm in the Netherlands, has for years been developing a closed-loop, cascaded thermoacoustic engine that can run on small temperature differences [10]. A relatively recent venture called "SoundEnergy" has been formed to commercialize this technology, specifically for providing building $\mathrm{A} / \mathrm{C}$ by harvesting waste heat.

The authors have not yet found reliable performance numbers for these devices; but they do claim to harvest $\sim 40 \%$ of the waste heat from flue gas at $300^{\circ} \mathrm{C}$, which is roughly consistent with their specification of $160^{\circ} \mathrm{C}$ as the minimum temperature for a liquid waste-heat source (that can, presumably, be directly applied to the heat exchanger of the engine). There are further claims from other Aster publications that the engines can convert $10 \%$ of the waste heat at $160^{\circ} \mathrm{C}$ into electricity. At cooling temperatures close to ambient, $\mathrm{COP}>1$ is common; if we assume the Aster cooling cycle achieves a COP of 2 , then that means at least $20 \%$ of the waste heat is converted into cooling power. To the authors, that sounds remarkably good.

The equipment involved does have a large footprint [10]. Note that a standard $25 \mathrm{~kW}$ commercial chiller is about a $1-\mathrm{m}$ cube), and the equipment discussed in [10] does not include the heat exchanger(s) necessary to harvest the waste heat. However, if the waste heat is available, and the space is available, then 
maybe this is a good solution. Published approximations for building requirements suggest an average of 1 "ton" chilling per 280 square feet for office spaces (this figure could be higher for equatorial climes), or $0.135 \mathrm{~kW} / \mathrm{m}^{2}$. Hence, a building 50 feet on a side with five floors would require about $312 \mathrm{~kW}$ of cooling, and (according to our assumptions) about $4 \mathrm{MW}$ of waste heat in the flue(s). This is a large amount of cooling relative to the Aster device, but recalling the scaling of thermoacoustic cooling requirements in the previous section, it is considerably less daunting than the refrigeration required for $\mathrm{CO}_{2}$ scrubbing in a $91 \mathrm{MW}$ power plant. The 1MW engine envisioned by Wollen et al [9] for wellhead gas liquefaction would, with a COP of 2 , produce $2 \mathrm{MW}$ of refrigeration at ambient temperatures, more than enough for many office buildings.

The ratio of raw exhaust heat to refrigeration suggested by the Aster technology is roughly $1 / 0.4 / 0.2$ or 12.5 . Studies [11] of building waste-heat exhaust suggest that this ratio is satisfied or exceeded by many factories that have heat-intense manufacturing, such as aluminum smelting or glass production. What is perhaps more significant for the purposes of this paper is that this heat is often hot enough to harvest for a low- $\Delta \mathrm{T}$ regenerative engine $\left(300-400^{\circ} \mathrm{C}\right)$, but not hot enough to run a steam turbine efficiently. By the evaluation criteria:

1. Does the use of a thermoacoustic device offer an improvement over current practice? Heat-driven airconditioning would be a major improvement over current practice, even if its use was limited to certain niches such as factories that produce a lot of waste heat.

2. Does a thermoacoustic device enable a process or technology that is currently not practical? Much of the waste heat from factories, etc. is not hot enough to drive a steam turbine, but it has been shown by Aster and SoundEnergy that acoustic cooling devices can use lower-grade heat. There are not currently very many competing systems that can make this claim.

3. In a given application, will a thermoacoustic device make good use of the resources in question, or could they be put to better use? The waste heat that would be harvested for air conditioning is currently not utilized, for the most part. If one could harvest the heat to make power instead of cooling, since $70 \%$ of the Kingdom's power goes to cooling, the extra transduction step would be wasteful.

According to these criteria, heat-driven thermoacoustic cooling is an attractive proposition for TA application.

\section{Waste-heat powered air-conditioning Subjective score: 6/10}

\subsection{Hydrogen liquefaction}

In many respects, Saudi Arabia is well-positioned for a posthydrocarbon world, with its abundant sunlight and water (albeit salt water). Water can be electrolyzed into hydrogen and oxygen, and if that electricity is provided via solar panels, then the fuel is "free" (neglecting, of course, the capital cost of the solar panels and electrolyzers). Since hydrogen burns clean, producing only water as a byproduct, sustainably produced hydrogen is an environmentally friendly fuel.

Though the water accessible to the Kingdom is mostly seawater, there are indications that seawater can be electrolyzed much like freshwater, with the right approach [12]. One of the well-known disadvantages of hydrogen as an energy source, however, is that hydrogen is gaseous at standard conditions, unlike oil and gasoline. In order to have high energy density, it must be either liquefied, compressed, or chemically synthesized into liquid fuel. While liquefying hydrogen is energy-intense, if that energy is in turn provided by waste or solar heat, then the resulting $\mathrm{LH}_{2}$ is still "sustainable". Thus, it is reasonable to suppose that liquefying hydrogen at the point of production might be a good application for heat-driven TA cooling.

A brief review of hydrogen's properties, and state of the art in hydrogen liquefaction, shows that this is probably not the case. The enthalpy change of hydrogen from gas at 0 psig and $300 \mathrm{~K}$ to liquid is $\Delta h=4 \mathrm{MJ} / \mathrm{kg}$, and only $500 \mathrm{~kJ}$ of that is latent heat. Most of the enthalpy change is in sensible heat, over a large temperature ratio $(300 \mathrm{~K}$ to $20 \mathrm{~K})$. One salient fact about thermoacoustic cooling, much like Stirling cooling, is that it works best at discrete temperatures, where the heat exchange happens at high energy density and nearly isothermally, as during a phase-change process. Gradual cooling over a large temperature difference is the province of recuperative cycles, and since the widespread adoption of single mixed-refrigerants in the process gas industry, these kinds of cycles have become much more efficient than their Brayton or Joule-Thomson predecessors, approaching $40 \%$ of Carnot or more at large scales. Large-scale hydrogen liquefaction is still costly, in terms of the energy penalty compared to direct use of the electric power required to produce it. According to one source [13]:

Liquid hydrogen storage requires refrigeration to a temperature of $20 \mathrm{~K}$, and the liquefaction process requires an industrial facility expending a minimum of $15.1 \mathrm{MJ} / \mathrm{kg}$. The actual energy spending is nearly three times higher for the refrigeration techniques available at the present, amounting to over $30 \%$ of the energy stored.

The mixed-refrigerant techniques mentioned above can't reach the actual liquefaction point of hydrogen, so the last part of the cycle involves compressing the pre-cooled hydrogen and then "flashing" it down. This part of the process is not particularly efficient, so there is a possible role for thermoacoustics as the last stage in the liquefaction. As a main cooling method, it is much better suited to applications where the sensible heat load is less dominant.

1. Does the use of a thermoacoustic device offer an improvement over current practice? Current practice is to use a simple Joule-Thomson expansion to achieve the liquefaction. A thermoacoustic cooler, especially if driven by a source of waste heat, would improve the liquefaction efficiency.

2. Does a thermoacoustic device enable a process or technology that is currently not practical? Thermoacoustic 
systems typically use helium as the working fluid, and one can imagine using a recuperative helium cycle (e.g. Brayton) for the last stage of cooling. It also may be feasible to use a reversible turbine expander in place of the JT valve, although using hydrogen as the working fluid in a turbine does present special challenges.

3. In a given application, will a thermoacoustic device make good use of the resources in question, or could they be put to better use? While in theory there is an efficiency improvement by replacing the $\mathrm{J}-\mathrm{T}$ expansion with a reversible cycle, the $\mathrm{J}$-T stage is a small part of the overall system efficiency, and it seems doubtful that a thermoacoustic system would pay for itself through reduced operating costs in a timely way.

\section{Hydrogen liquefaction subjective score: 2/10}

\subsection{Zero-boiloff LH2 storage}

If liquefaction of ambient-temperature hydrogen gas is a poor fit to a regenerative cycle like a TA cooler, recondensing vapor in a storage vessel is a perfect fit. All the heat exchange happens at saturation, at a temperature too low for the industrystandard SMR (single-mixed refrigerant) methods to reach. Already, thermoacoustic "pulse-tube" coolers are a standard method of providing zero-boiloff liquid nitrogen dewars for biostorage [14]. Another advantage of this application for thermaocoustics is that the scale of cooling capacity required is not vastly different from existing thermoacoustic applications. Because the liquid is recondensing, a large surface area is not required, as it is for recuperative cooling.

In a storage dewar or vessel, heat leaking in from the outside raises the stored liquid's temperature and pressure inside. When the pressure exceeds the safe limit of the vessel, vapor must be vented to the outside. This is more a matter of convenience than cost for laboratory storage freezers that use liquid nitrogen, as nitrogen is cheap and harmless to vent (in small quantities). But hydrogen is expensive, and because it must be stored at such a cold temperature, it is more susceptible to boil-off.

It is estimated that about $12 \%$ of the hydrogen is typically lost to boiloff in a passive storage tank rather than being used or delivered. Suppose an actively cooled surface is inserted in the "ullage" or vapor space in the top of the vessel to recondense the vapor. In that case, the hydrogen can be stored indefinitely without any product loss. However, in the absence of a mature, efficient method of recondensing, a zero-boiloff dewar is not economical.

Notardando et al. [15] have shown a schematic of a zeroboiloff LH2 storage vessel. The mention of the water chiller having a cooling capacity of $96 \mathrm{~kW}$ thermal is a clue to the electric consumption of the hydrogen recondensing system. The equipment is identified as a Linde LR1620 refrigerator, driven by the Linde RSX compressor. From another source that uses a similar Linde refrigerator [16], driven by the same compressor, we have, the helium refrigerator LINDE-1630 with an RSX compressor in refrigeration mode has a cooling power of 86 Watts without and 151 Watts with nitrogen pre-cooling at helium flow rate of $22.2 \mathrm{~g} / \mathrm{sec}$ and an electrical power consumption of $110 \mathrm{~kW}$. The application in this source was at a lower temperature, so the cooling power was lower. In Notardando et al. [15], the refrigerator rated capacities of $880 \mathrm{~W}$ and $390 \mathrm{~W}$ were reported at $20 \mathrm{~K}$, with and without and $\mathrm{LN}_{2}$ pre-cooling respectively, and employs independent instrumentation and command and control. The cycle is driven by an RSX helium compressor.

From this, we can gather that the power consumption of the refrigeration system is approximately $110 \mathrm{~kW}$, not counting the water chiller itself. The heat load, on the other hand, is just the heat leak of the 125,000 liter vessel, which was measured at 300 watts. These values imply a first-law efficiency of $0.27 \%$ and a second-law efficiency of only $3.7 \%$. It seems entirely possible that a two-stage heat-driven thermoacoustic chiller could easily outdo this efficiency while running off waste or solar heat.

An economic justification for a reliquefier can be attempted by using publicly available pricing. According to a presentation [17] by Lawrence Livermore National Laboratory (LLNL), the minimum sell price of bulk liquid hydrogen is $\$ 5 / \mathrm{kg}$; REFPROP [18] (thermodynamic software from NIST) gives the density of liquid (para)hydrogen at 1 atm as $0.071 \mathrm{~kg} / \mathrm{liter}$. Hence, a 125,000 -liter tank can hold as much as $8850 \mathrm{~kg}$. Using the heat leak of $300 \mathrm{~W}$ [15], the tank loses about $62 \mathrm{~kg}$ per day, or $0.7 \%$ /day (in line with estimates from the LLNL). This amounts to at least $\$ 300$ in lost value every day. For the operating cost, note that in KSA, the average price industry paid for electricity in 2019 was $6.8 \notin$ per $\mathrm{kWh}$ [19]. At $110 \mathrm{~kW}$ continuous, the liquefier system in [15] would cost $\$ 0.068 \times 110 \times 24=\$ 180$ per day, or $\$ 65,500$ year. Hence, the operating cost is almost $2 / 3$ the value of the lost product; in the US and Europe, electricity costs are closer to $14 \phi / \mathrm{kWh}$, so if this system were located outside KSA, the operating cost could exceed the value of the lost $\mathrm{LH}_{2}$. Therefore, even without considering capital cost, the Linde refrigerator system is only marginally economical. A TA solution that reduces or even eliminates most of the operating cost could make ZBO LH2 feasible.

1. Does the use of a thermoacoustic device offer an improvement over current practice? Current practice is still in the prototype stages, with very low efficiency. Even without driving a TA system with waste heat, the efficiency gain would be substantial.

2. Does a thermoacoustic device enable a process or technology that is currently not practical? The efficiency of current demonstration systems is low enough that the economic value is marginal; if a TA system can be made for the same or similar capital cost, it would make $\mathrm{ZBO} \mathrm{LH}_{2}$ storage practical. The capital cost of a thermoacoustic system is the big unknown in this equation.

3. In a given application, will a thermoacoustic device make good use of the resources in question, or could they be put to better use? If $\mathrm{LH}_{2}$ is already part of the energy infrastructure, 
then boiloff mitigation is necessary and there are currently no good solutions.

\section{Zero-boiloff LH2 storage subjective score: 9/10}

\section{CONCLUSIONS}

To review, here are the applications considered, together with their subjective scores and a brief explanation:

1. Cryogenic Carbon Capture (3/10). This application dovetails nicely with work already underway with SES at KAUST, for capturing carbon from the exhaust of power plants. However, given realistic efficiencies of both engine and cooler, only a fraction of the carbon can be captured if the cycle is powered by the waste heat in the exhaust. The scale of the cooling required, the process temperature, and the availability of $550^{\circ} \mathrm{C}$ waste heat also suggests that a steam-driven recuperative cycle (mixed refrigerant, Claude, etc.) might be a better fit to this application (that, or a bottoming cycle to generate more electricity and reduce the specific $\mathrm{CO}_{2}$ generation rate, $\mathrm{kg} / \mathrm{kWhe.)}$

2. Waste-heat powered air conditioning / water chilling (6/10). Aster Thermoacoustics has already spent decades developing technology for exactly this niche, and has a credible claim to being at least technically ready for industrial deployment. The available waste heat, and scale of cooling required, makes a thermoacoustic solution at least plausible for many factories with heat-intensive manufacturing.

3. Hydrogen liquefaction (2/10) Because most of the enthalpy change in hydrogen liquefaction is in sensible heat removal, recuperative cycles have a huge advantage. A heat-powered TA cooler could replace the last, irreversible J-T expansion, but it seems unlikely the cost would be justified.

4. Zero-boiloff LH2 storage (9/10). This application is perfectly suited to a multi-stage acoustic cryocooler, both in terms of process and in terms of scale, and is not well-suited to existing technology.

The clear winner out of the candidate applications is zeroboiloff $\mathrm{LH}_{2}$ storage. $\mathrm{ZBO} \mathrm{LH} 2$ storage using thermoacoustics is plausible, improves upon current practice, and does not use a resource that would be better employed elsewhere or compete with an established conventional technology. The next most promising candidate is waste-heat powered air-conditioning, which also has a scaled up commercial opportunity in the Kingdom.

\section{ACKNOWLEDGMENTS}

The research reported in this publication was supported by the Clean Combustion Research Center (CCRC) of the King Abdullah University of Science and Technology (KAUST), under the CCF fund grant (URF/1/1975-15).

\section{REFERENCES}

[1] G. W. Swift, Thermoacoustics: A unifying perspective for some engines and regenerators, 2nd ed., Springer, 2017.

[2] Baxter L., Baxter A., Burt S., "Cryogenic CO2 capture as a cost-effective CO2 capture process," Proceedings of the $26^{\text {th }}$ International Pittsburgh Coal Conference 1, p. 761 (Pittsburgh, PA, 20-23 September 2009)

[3] Struck, C., Wit, Jan de, Weersink, A., Brus, W., Owczarek, P., Kees de Blok, Berkhout, H., Towards the application of thermoacoustic cooling in office buildings: performance governing parameters and models for performance predictions, CLIMA 2016 - proceedings of the 12th REHVA World Congress, 2016.

[4] Backhaus, S.; Swift, G. W., "A thermoacoustic Stirling heat engine." Nature 399, pp. 335-338, 1999.

[5] Sayre, A., Frankman, D., Baxter, A., Stitt, K., Baxter, L., Field Testing of Cryogenic Carbon Capture, Carbon Management Technology Conference, 2017.

[6] Electricity \& Cogeneration Regulatory Authority (ECRA)

Statistical Booklet for 2018, pp. 19-21, available at

https://www.ecra.gov.sa/en-

us/MediaCenter/DocLib2/Pages/SubCategoryList.aspx?categor $\mathrm{yID}=5$

[7] GE 7E Product Brochure available at

https://www.ge.com/content/dam/gepower-

pgdp/global/en_US/documents/product/gas $\% 20$ turbines/Fact $\%$

20Sheet/7e03-brochure.pdf

[8] NIST Chemistry WebBook, National Institute of Standards

\& Technology, US Department of Commerce,

https://webbook.nist.gov/cgi/cbook.cgi?ID=C124389\&Mask=4

[9] Wollen, J., Swift, G., Backhaus, S., and Gardner, D., "Development of a Thermoacoustic Natural Gas Liquefier," 2002 AIChE New Orleans Meeting, New Orleans, LA, March

2002; also available as a public report from the Los Alamos

National Laboratory, report \# LA-UR-02-1623.

[10] http://www.aster-thermoacoustics.com/

[11] Nowicki, C., Gosselin, L. "An Overview of Opportunities for Waste Heat Recovery and Thermal Integration in the Primary Aluminum Industry," JOM 64, 990-996, 2012.

[12] https://news.stanford.edu/2019/03/18/new-way-generatehydrogen-fuel-seawater/

[13] Sørensen, B., editor. Hydrogen and Fuel Cells: Emerging

Technologies and Applications, 2nd edition, 2012.

[14] http://www.chartindustries.com/Life-Sciences/StainlessSteel-Cryogenic-Freezers/MVE-Fusion-Series

[15] Notardonato, W.U., Zero boil-off methods for large-scale liquid hydrogen tanks using integrated refrigeration and storage, IOP Conf. Ser.: Mater. Sci. Eng., Vol. 278, 2017.

[16] Sekachev, J., TRIUMF cyclotron vacuum system refurbishing, J. Phys.: Conf. Ser., Vol. 100, 2008.

[17] Petitpas, G., Thermodynamic and Economic Modeling of Boil-off Losses in Liquid Hydrogen Handling Processes, presentation by Lawrence Livermore National Laboratory to the Department of Energy's Fuel Cell Technologies Office, June 2018. 
[18] Reference Fluid Thermodynamic and Transport Properties Database (REFPROP) version 8 , published by the National Institute of Standards and Technology (NIST); see https://www.nist.gov/programs-projects/reference-fluid-

thermodynamic-and-transport-properties-database-refprop.

[19] https://www.globalpetrolprices.com/Saudi-

Arabia/electricity_prices/ 